\title{
Efficacy of dexamethasone added to ramosetron for preventing postoperative nausea and vomiting in highly susceptible patients following spine surgery
}

\author{
So-Young Yang ${ }^{1}$, Na-Hyung Jun ${ }^{1}$, Yong-Seon Choi ${ }^{1,2}$, Jong Chan Kim ${ }^{1}$, Jae-Kwang Shim ${ }^{1,2}$, \\ Sang-Hee $\mathrm{Ha}^{1}$, and Young Lan Kwak ${ }^{1,2}$ \\ ${ }^{1}$ Department of Anesthesiology and Pain Medicine, ${ }^{2}$ Anesthesia and Pain Research Institute, Yonsei University College of Medicine, \\ Seoul, Korea
}

Background: Opioid-based patient controlled analgesia (PCA) provides adequate pain control following spinal surgeries at the expense of increased risk of postoperative nausea and vomiting (PONV). We evaluated the efficacy of dexamethasone added to ramosetron, which is a newly developed five-hydroxytryptamine receptor 3 antagonist with a higher receptor affinity and longer action duration compared to its congeners, on preventing PONV in highly susceptible patients receiving opioid-based IV PCA after spinal surgery.

Methods: One hundred nonsmoking female patients undergoing spinal surgery were randomly allocated to either a ramosetron group (group R) or a ramosetron plus dexamethasone group (group RD)., Normal saline (1 ml) or $5 \mathrm{mg}$ of dexamethasone was injected before anesthetic induction, while at the end of the surgery, ramosetron $(0.3 \mathrm{mg})$ was administered to all patients and fentanyl-based IV PCA was continued for $48 \mathrm{hrs}$. The incidence and severity of PONV, pain score and the amount of rescue antiemetics were assessed for 48 hours after surgery.

Results: The number of patients with moderate to severe nausea (20 vs. $10, P=0.029$ ), and overall incidence of vomiting (13 vs. $5, \mathrm{P}=0.037$ ) were significantly lower in the group $\mathrm{RD}$ than in the group $\mathrm{R}$, respectively. Rescue antiemetic was used less in the $\mathrm{RD}$ group without significance.

Conclusions: Combination of ramosetron and dexamethasone significantly reduced the incidence of moderate to severe nausea and vomiting compared to ramosetron alone in highly susceptible patients receiving opioid-based IV PCA after surgery. (Korean J Anesthesiol 2012; 62: 260-265)

Key Words: Analgesia, Dexamethasone, Nausea, Ramosetron, Vomiting.

Received: April 12, 2011. Revised: 1st, May 30, 2011; 2nd, June 22, 2011; 3rd, June 30, 2011. Accepted: July 1, 2011.

Corresponding author: Young Lan Kwak, M.D., Ph.D., Department of Anesthesiology and Pain Medicine, Anesthesia and Pain Research Institute, Yonsei University College of Medicine, 134, Shinchon-dong, Seodaemun-gu, Seoul 120-752, Korea. Tel: 82-2-2228-8513, Fax: 82-2-3642951,E-mail: ylkwak@yuhs.ac

(ㄷ) This is an open-access article distributed under the terms of the Creative Commons Attribution Non-Commercial License (http:// creativecommons.org/licenses/by-nc/3.0/), which permits unrestricted non-commercial use, distribution, and reproduction in any medium, provided the original work is properly cited. 


\section{Introduction}

Posterior spinal surgery is usually accompanied by more severe postoperative pain than other neurosurgical treatments and therefore requires adequate pain control to enable a fast recovery. For that purpose, patient controlled analgesia (PCA) using opioids is being widely used which has been proved to provide high satisfaction rates for postoperative pain control at the expense of increased risk of postoperative nausea and vomiting (PONV) [1-3]. Vomiting may cause dehydration, electrolyte imbalance, disruption of the surgical repairs, and increases the perception of pain affecting patient outcome $[4,5]$. Also, increased pressure on the abdominal contents due to nausea and vomiting would be transmitted to the inferior vena cava, and then, to the epidural venous system, which causes increased bleeding [6]. PONV is a significant problem for neurosurgical patients affecting patient outcome which mandates therapies aimed at active prevention. Thus, recommendations for the treatment of established PONV based on trials in neurosurgical patients may be flawed [7].

Five-hydroxytryptamine receptor $3\left(5-\mathrm{HT}_{3}\right)$ antagonists are the most extensively studied antiemetic agents which were demonstrated to possess better anti-vomiting efficacy than anti-nausea efficacy $[8,9]$. In a recent meta- analysis, the ability of $5-\mathrm{HT}_{3}$ antagonists including ondansetron and granisetron to prevent PONV was reported not to be satisfactory, although they could reduce the cumulative incidence of emesis [10]. Ramosetron is a newly developed $5-\mathrm{HT}_{3}$ antagonist with higher receptor affinity and a longer duration of action than its congeners such as ondansetron and granisetron $[11,12]$. In a recent study, ramosetron demonstrated promising results with regard to reduction of nausea severity compared to ondansetron in spinal surgical patients with high susceptibility for developing PONV [12].

Regarding the multifactorial etiologies of PONV, combinations of antiemetics from different classes could be a more effective antiemetic treatment modality [13], and dexamethasone added to $5-\mathrm{HT}_{3}$ antagonists was reported to enhance antiemetic efficacy with negligible side-effects in some surgical setting $[14,15]$. However, the efficacy of dexamethasone in patients treated with opioid-based intravenous (IV) PCA was evaluated scantly and no comprehensive data exist regarding the antiemetic efficacy of ramosetron and dexamethasone following spinal surgery. The purpose of this study was to evaluate the efficacy of ramosetron and dexamethasone combination therapy against ramosetron alone on PONV in highly susceptible patients receiving opioid-based IV PCA after surgery in a prospective, randomized and double-blinded trial.

\section{Materials and Methods}

Approval from the institutional review board and informed consent from patients were obtained. Before anesthesia, the expected risk for PONV was calculated using the simplified risk score system of Apfel et al. [16], which uses 4 risk factors, including female gender, smoking, the use of postoperative opioids and prior history of motion sickness or PONV. The risk score is constructed according to the number of significant risk factors in the logistic regression analysis; the presence of $0,1,2$, 3 , or 4 of these risk factors correspond to approximately 10,20 , 40,60 , and $80 \%$ risk for PONV, respectively. We recruited 100 female patients, aged 18 to 65 , scheduled for elective lumbar spinal surgery using a standard posterior approach, between March 2008 and January 2009. To minimize the confounding effect of the operation, only the patients undergoing less than two levels of lumbar spinal operation were studied. Basic inclusion criteria were nonsmoking, female patients and all patients were scheduled to receive IV PCA using high-dose opioids. The minimal expected risk for PONV was $60 \%$ in this study. Exclusion criteria were severe impairment of bowel motility, insulin-dependent diabetes mellitus, pregnancy or breastfeeding, administration of antiemetic medication within $24 \mathrm{~h}$ before operation, systemic treatment with steroids within $24 \mathrm{~h}$ before operation or during $48 \mathrm{~h}$ after operation, a history of cardiovascular or respiratory disease, active alcohol or drug usage, obesity (body mass index $\geq 35 \mathrm{~kg} / \mathrm{m}^{2}$ ), as well as impaired renal and/or hepatic function. Patients with inadvertent tear of the dura mater during the surgery were also excluded. Patients were randomly allocated into either ramosetron group (group $\mathrm{R}, \mathrm{n}=50$ ) or combination of ramosetron and dexamethasone group (group $\mathrm{RD}, \mathrm{n}=50$ ) by a computerized randomization table.

Patients were premedicated with midazolam $(0.05 \mathrm{mg} /$ $\mathrm{kg}$ ) and glycopyrrolate $(0.004 \mathrm{mg} / \mathrm{kg})$. Before the induction of anaesthesia, $1 \mathrm{ml}$ of normal saline was injected in patients assigned to group $\mathrm{R}$ and dexamethasone (5 $\mathrm{mg}$ in $1 \mathrm{ml}$ ) was injected in patients assigned to group RD. Injected drugs were prepared in $1 \mathrm{ml}$ syringes by anesthetic nurses who were not involved in this study. Anaesthesia was induced with $1.5-2.0 \mathrm{mg} /$ $\mathrm{kg}$ of propofol, and $0.5-1 \mu \mathrm{g} / \mathrm{kg}$ of remifentanil, and tracheal intubation was facilitated with $0.9 \mathrm{mg} / \mathrm{kg}$ of rocuronium. Patients' lungs were mechanically ventilated with oxygen and air (inspired oxygen fraction 0.4 ), a tidal volume of $6-8 \mathrm{ml} / \mathrm{kg}$, and $\mathrm{I}$ : $\mathrm{E}$ ratio of $1: 2.0$ at a respiratory rate of $8-12$ breaths $/ \mathrm{min}$ to maintain normocarbia throughout operation. Anaesthesia was maintained with continuous infusion of remifentanil (0.05-0.2 $\mu \mathrm{g} / \mathrm{kg} / \mathrm{min})$, rocuronium (5-6 $\mu \mathrm{g} / \mathrm{kg} / \mathrm{min})$, and sevoflurane (1.5-2.5\%). At the end of the operation, all patients received ramosetron $(0.3 \mathrm{mg})$ and PCA was initiated. The PCA 
regimen consisted of fentanyl (25 $\mu \mathrm{g} / \mathrm{kg})$, ketorolac (120 mg) and ramosetron ( $0.3 \mathrm{mg}$; total volume including saline, $100 \mathrm{ml}$ ). The IV PCA was programmed to deliver $2 \mathrm{ml} / \mathrm{h}$ as background infusion and $1 \mathrm{ml}$ per demand with a 15 min lockout for a $48 \mathrm{~h}$ period. As patients were placed in the supine position, sevoflurane was discontinued and remifentanil was infused continuously at a reduced infusion rate $(0.02-0.05 \mu \mathrm{g} / \mathrm{kg} / \mathrm{min})$. Neuromuscular blockade was antagonized with pyridostigmine $(0.1 \mathrm{mg} / \mathrm{kg})$ and glycopyrrolate $(0.2-0.3 \mathrm{mg})$, and remifentanil was discontinued after extubation.

Primary efficacy variables assessed included the incidence and severity of nausea and incidence of vomiting in the first 48 $\mathrm{h}$ following emergence from general anaesthesia. Secondary efficacy variables included use of additional antiemetic rescues, pain intensity and medication-associated complications. These variables were assessed by two investigators who were blinded to treatment group. Evaluations were performed at the following 4 time periods: during the stay in the recovery room and in the ward at approximately $6 \mathrm{~h}, 6-24 \mathrm{~h}$, and $24-48 \mathrm{~h}$. Nausea was defined as subjectively unpleasant sensation associated with awareness of the urge to vomit and an emetic episode was defined as a single episode of vomiting (the forceful expulsion of gastric contents through the mouth). Retching, which was considered as vomiting, was defined as an expulsive movement of the stomach muscles when no stomach contents were expelled. The intensity of nausea was graded on verbal rating scales (VRS) using an 11 point scale, with $0=$ no nausea to $10=$ worst possible nausea. The severity of nausea was graded on VRS: mild ( $1-3)$, moderate $(4-6)$, and severe $(7-10)$. Pain intensity scores were measured using a visual analog scale (VAS) that ranged from $0 \mathrm{~mm}$ (no pain) to $100 \mathrm{~mm}$ (worst pain imaginable). Rescue antiemetic therapy (metoclopromide 10 $\mathrm{mg}, \mathrm{IV}$ ) was given at the discretion of the attending physicians, who were blinded to the patients' group, in response to nausea, vomiting or at the patient's request. IV PCA was discontinued when severe nausea persisted and/or upon patient's request after 2 consecutive boluses of metoclopromide. The patients were allowed to receive ketorolac ( $30 \mathrm{mg}$, IV) if they complained of pain $\geq 50 \mathrm{~mm}$ on VAS. The most frequently reported side effects of the $5-\mathrm{HT}_{3}$ antagonists used in conjunction with opioid-based IV PCA such as headache, dizziness, drowsiness, constipation, flushing, heat and general weakness were also assessed during the study period.

\section{Statistical analysis}

Sample size estimation was performed in accordance with the results of a study comparing the effect of ondansetron with dexamethasone on PONV in a high risk group of patients [13]. Forty-three patients per group was determined to be adequate to demonstrate a $28 \%$ reduction in the incidence of PONV (from $47 \%$ to $19 \%$ ) with an at $\alpha=0.05$ and $\beta=0.8$. Statistical analyses were performed with SPSS 13.0 (SPSS Inc., Chicago, IL, USA). All data are expressed as means (SD), number or median (interquartile range). Data between the groups were compared using a Chi-square test, Fisher's exact test, independent t-test or the Mann-Whitney U test, as appropriate. A P value of less than 0.05 was considered statistically significant.

\section{Results}

Patient characteristics including history of PONV and/or motion sickness as well as operative data were similar between the groups (Table 1). Sixteen patients in each group had 4 risk factors and the remaining patients had 3 risk factors for PONV. Operations performed were lumbar laminectomy in 23 and 21 patients, and lumbar spinal fusion in 27 and 29 patients in the R and RD groups, respectively. None of the patients had inadvertent tears of the dura mater. PCA pumps were discontinued in one patient each in both groups due to

Table 1. Patient Characteristics

\begin{tabular}{lccc}
\hline & $\begin{array}{c}\text { Group R } \\
(\mathrm{n}=50)\end{array}$ & $\begin{array}{c}\text { Group RD } \\
(\mathrm{n}=50)\end{array}$ & P value \\
\hline Age $(\mathrm{yr})$ & $48.8 \pm 12.3$ & $49.8 \pm 9.2$ & 0.626 \\
Body mass index $\left(\mathrm{kg} / \mathrm{m}^{2}\right)$ & $23.5 \pm 2.9$ & $24.2 \pm 2.6$ & 0.220 \\
Surgery time $(\mathrm{min})$ & $112.4 \pm 46.2$ & $124.7 \pm 51.8$ & 0.213 \\
Anesthesia time $(\mathrm{min})$ & $149.0 \pm 52.9$ & $166.9 \pm 56.2$ & 0.104 \\
Amount of fentanyl used $(\mu \mathrm{g})$ & $1,384.0 \pm 159.5$ & 1 & 0.432 \\
History of PONV & 6 & 16 & 0.111 \\
History of motion sickness & 13 & $34(68)$ & 0.507 \\
Simplified risk score & $34(68)$ & $16(32)$ & \\
3 & $16(32)$ & & \\
4 & & & \\
\hline
\end{tabular}

Values are expressed as means \pm SD or number of patients. Group R: ramosetron only, Group RD: combination of ramosetron and dexamethasone, PONV: postoperative nausea and vomiting. 
Table 2. Incidence of Nausea, Vomiting, and Requirement for Rescue Antiemetic Treatment

\begin{tabular}{|c|c|c|c|}
\hline & $\begin{array}{l}\text { Group R } \\
(\mathrm{n}=50)\end{array}$ & $\begin{array}{l}\text { Group RD } \\
(\mathrm{n}=50)\end{array}$ & $P$ value \\
\hline PONV & $29(58)$ & $24(48)$ & 0.316 \\
\hline Nausea frequency/intensity & $26(52) / 1[0-5]^{*}$ & $22(44) / 0[0-3]^{*}$ & $0.423 / 0.239$ \\
\hline $\mathrm{RR}$ & $5(10)$ & $6(12)$ & 0.521 \\
\hline $0-6 \mathrm{hr}$ & $21(42) / 0[0-0]$ & $15(30) / 0[0-2]$ & $0.184 / 0.124$ \\
\hline $6-24 \mathrm{hr}$ & $19(38) / 0[0-5]$ & $17(34) / 1[0-1.5]$ & $0.732 / 0.521$ \\
\hline $24-48 \mathrm{hr}$ & $14(28) / 0[0-1.5]$ & $13(26) / 1[0-1]$ & $0.821 / 0.684$ \\
\hline Nausea $\geq$ VRS 4 & $20(40)$ & $10(20)$ & $0.029^{\dagger}$ \\
\hline $\mathrm{RR}$ & $2(4)$ & 0 & 0.124 \\
\hline $0-6 \mathrm{hr}$ & $16(32)$ & $7(14)$ & $0.032^{\dagger}$ \\
\hline $6-24 \mathrm{hr}$ & $12(24)$ & $6(12)$ & 0.118 \\
\hline $24-48 \mathrm{hr}$ & $7(14)$ & $4(8)$ & 0.338 \\
\hline Vomiting & $13(26)$ & $5(11)$ & $0.037^{\dagger}$ \\
\hline $\mathrm{RR}$ & $1(2)$ & 0 & 0.367 \\
\hline $0-6 \mathrm{hr}$ & $8(16)$ & $3(6)$ & 0.102 \\
\hline $6-24 \mathrm{hr}$ & $7(14)$ & $3(6)$ & 0.318 \\
\hline $24-48 \mathrm{hr}$ & $3(6)$ & $1(2)$ & 0.617 \\
\hline Rescue antiemetic & $22(44)$ & $14(28)$ & 0.096 \\
\hline $\mathrm{RR}$ & $2(4)$ & $2(4)$ & 0.622 \\
\hline $0-6 \mathrm{hr}$ & $13(26)$ & $6(12)$ & 0.066 \\
\hline $6-24 \mathrm{hr}$ & $13(26)$ & $7(14)$ & 0.147 \\
\hline $24-48 \mathrm{hr}$ & $5(10)$ & $4(8)$ & 1.000 \\
\hline
\end{tabular}

Values are expressed as number (\%) or median [interquatile range]. Group R: ramosetron only, Group RD: combination of ramosetron and dexamethasone, PONV: total number of patients who experienced nausea or vomiting during study period, RR: recovery room, Intensity of nausea was graded using VRS, VRS: verbal rating scale. *Median of the highest verbal rating scores of nausea intensity during study period, ${ }^{\dagger}$ Indicates a significant difference between the two groups.

Table 3. Pain Intensity Scores

\begin{tabular}{lccc}
\hline & $\begin{array}{c}\text { Group R } \\
(\mathrm{n}=50)\end{array}$ & $\begin{array}{c}\text { Group RD } \\
(\mathrm{n}=50)\end{array}$ & P value \\
\hline Pain scores & & & \\
$\mathrm{RR}$ & $21.7 \pm 20.7$ & $29.7 \pm 19.6$ & 0.092 \\
$0-6 \mathrm{hr}$ & $40.6 \pm 27.5$ & $36.0 \pm 18.6$ & 0.336 \\
$6-24 \mathrm{hr}$ & $30.0 \pm 24.7$ & $34.5 \pm 20.1$ & 0.365 \\
$24-48 \mathrm{hr}$ & $32.7 \pm 21.7$ & $27.6 \pm 18.1$ & 0.416 \\
\hline
\end{tabular}

Values are expressed as means \pm SD. Group R: ramosetron only, Group RD: combination of ramosetron and dexamethasone, RR: recovery room.

intractable nausea and/or vomiting.

The overall incidence of nausea was $52 \%$ in group $\mathrm{R}$ and $44 \%$ in group RD. Although the median of the highest VRS scores of nausea intensity during study period was similar between the groups, the number of patients with moderate to severe nausea was significantly lower in the RD group $(\mathrm{P}=0.029)$. The difference was more prominent early in the postoperative period. The overall incidence of vomiting was significantly lower in the group $\mathrm{RD}$ than in the group $\mathrm{R}(\mathrm{P}=0.037$; Table 2$)$.

Pain scores assessed up to $48 \mathrm{~h}$ after surgery were similar between the groups (Table 3 ).

No patient was withdrawn from the study due to adverse events associated with antiemetic medications. The number of patients who experienced antiemetics-related adverse events
Table 4. Side Effects of Antiemetic Drugs and Surgery-related Complications

\begin{tabular}{lccc}
\hline & $\begin{array}{c}\text { Group R } \\
(\mathrm{n}=50)\end{array}$ & $\begin{array}{c}\text { Group RD } \\
(\mathrm{n}=50)\end{array}$ & P value \\
\hline Headache & & & \\
$0-6 \mathrm{~h}$ & $3(6)$ & $3(6)$ & 1.000 \\
$6-24 \mathrm{~h}$ & $6(12)$ & $4(8)$ & 0.741 \\
$24-48 \mathrm{~h}$ & $6(12)$ & $4(8)$ & 0.505 \\
Dizziness & & & \\
$0-6 \mathrm{~h}$ & $5(10)$ & $5(10)$ & 1.000 \\
$6-24 \mathrm{~h}$ & $7(14)$ & $4(8)$ & 0.356 \\
$24-48 \mathrm{~h}$ & $6(12)$ & $5(10)$ & 0.749 \\
Drowsiness & & & \\
$0-6 \mathrm{~h}$ & $3(6)$ & $1(2)$ & 0.362 \\
$6-24 \mathrm{~h}$ & $3(6)$ & $2(4)$ & 1.000 \\
$24-48 \mathrm{~h}$ & $1(2)$ & $3(6)$ & 0.617 \\
Constipation & $1(2)$ & $1(2)$ & 1.000 \\
Total adverse event of antiemetics & $22(44)$ & $17(34)$ & 0.386 \\
Surgery-related complication & & & \\
$\quad$ Wound dehiscence & 0 & 0 & 1.000 \\
$\quad$ Fever $\left.>38^{\circ} \mathrm{C}\right)$ & $7(14)$ & $2(4)$ & 0.159 \\
$\quad$ Leukocytosis $\left(>10^{4} / \mu \mathrm{l}\right)$ & $5(10)$ & $10(20)$ & 0.161 \\
\hline
\end{tabular}

Values are expressed as number (\%). Group R: ramosetron only, Group RD: combination of ramosetron and dexamethasone.

during postoperative period was similar between the groups. There were no side effects such as increased risk of infection and wound dehiscence associated with the use of a single dose of dexamethasone (Table 4). 


\section{Discussion}

In this prospective, randomized study comparing the efficacies of ramosetron with that of ramosetron plus dexamethasone for preventing fentanyl-based IV PCA-related PONV in highly susceptible patients undergoing spinal surgery, the combination of ramosetron and dexamethasone significantly reduced the incidence of moderate to severe nausea and vomiting compared to those of ramosetron alone, although the incidence of total PONV was similar between the groups.

Inadequate treatment of postoperative pain and PONV may result in adverse physical and psychological outcomes [17], and PONV may increase patient's discomfort and also increase costs and unwarranted side effects [18].

$5-\mathrm{HT}_{3}$ antagonists are the most commonly used antiemetic agents for the prevention of PONV. However, previously reported results about their effects on preventing PONV were not satisfactory $[4,19]$. It seemed to be associated with the fact that 5 - $\mathrm{HT}_{3}$ antagonists possess better antivomiting than antinausea efficacy $[8,9]$. In our previous study [12], the incidence of PONV was $60-70 \%$ in patients with multiple risk factors for PONV in spite of ondansetron or ramosetron administration. The need for more effective antiemetic therapy is thus increasing and the limited efficacy of single antiemetics treatment has prompted evaluation of combination of antiemetic drugs acting at different receptor sites to prevent PONV [20]. Because of the multifactorial etiology of PONV, there has been increasing interest in using a combination of antiemetics from different classes for PONV prophylaxis. The antiemetic efficacy of combination of dexamethasone with earlier serotonin receptor antagonists such as ondansetron, granisetron and dolasetron was reported to be beneficial for reducing the incidence of PONV in several studies [14,21-23]. Hypotheses for why there is a better effect of combination therapy are as follows: 1) corticosteroids may reduce the levels of serotonin in neural tissue by depleting its precursor tryptophan 2) antiinflammatory properties of corticosteroids may prevent the release of serotonin in the gut 3) dexamethasone may potentiate the main effect of other antiemetics by sensitizing the pharmacological receptor $[21,24,25]$. Addition of dexamethasone to $5-\mathrm{HT}_{3}$ antagonist reduced the incidence of PONV [14] or improved quality of recovery, resulting in greater satisfaction for the management of PONV [23] compared to $5-\mathrm{HT}_{3}$ antagonists alone. However, little evaluation for the efficacy of combination of dexamethasone and $5-\mathrm{HT}_{3}$ antagonist in patients treated with opioid based PCA has been performed [26].

Ramosetron is a newly developed $5-\mathrm{HT}_{3}$ antagonist with a higher affinity and longer duration of action than that of the previously developed $5-\mathrm{HT}_{3}$ antagonists such as ondansetron, granisetron and tropisetron $[11,12]$. The effect of dexamethasone added to ramosetron in patients using opioid-based IV PCA with high susceptibility for PONV was evaluated first in this study and several beneficial effects could be demonstrated. The combination of ramosetron and dexamethasone could significantly reduce the incidence of moderate to severe nausea and vomiting compared to ramosetron alone. In addition, there was a trend toward less use of rescue antiemetic agents in the combination group. The finding that the incidence of moderate to severe nausea was significantly lower in the combination group seems to be promising considering that moderate to severe nausea comes just before vomiting and that it is vomiting which causes dehydration, disruption of the surgical repair, and increases the perception of pain $[4,5]$.

Total incidence of PONV, however, was not different between the groups and still half of the patients developed PONV even with combination therapy in this study. In a large trial to compare the efficacy of six antiemetic interventions and their combinations [27], increasing the number of antiemetics reduced the relative risk by $26 \%$, where as the degree of risk reduction with dexamethosone was about $18 \%$ in this study. The still higher incidence of PONV in the current study might be associated with high dose fentanyl in the IV PCA. In contrast to that large amount of fentanyl continuously infused for 48 $\mathrm{h}$ in this study, small boluses of opioids were intermittently administered at the discretion of the anesthesiologists in a previous study [28]. In addition, longer duration of observation for PONV lasting $48 \mathrm{~h}$ could also be responsible for the relatively higher incidence of PONV in this study compared to that of previous studies in which patients were mostly observed only for $24 \mathrm{~h}$ postoperatively. And total IV anesthesia with propofol or neuraxial analgesia also may be helpful in lowering the incidence of relatively high rates of PONV $[7,28]$.

A limitation of this study is as follows: the minimum effective dose of dexamethasone to reduce the incidence of PONV when combined with ondansetron has been reported to be $4 \mathrm{mg}$ in patients undergoing gynecological laparoscopy [21]. Moreover, cautious use of dexamethasone is recommended in surgical patients due to the concerns about surgery-related side effects, such as delayed wound healing and increased incidence of wound infection. Yet, evidence with regard to the appropriate dose of dexamethasone as an adjunct to prevent opioid based IV PCA related PONV has been limited and although beneficial effects could be demonstrated, the chosen dose in the current trial may be relatively small.

Combination of ramosetron and dexamethasone significantly reduced the incidence of moderate to severe nausea and vomiting compared to ramosetron alone, although the overall incidence of PONV was similar in both groups in highly susceptible patients for PONV using fentanyl-based IV PCA following spinal surgery using volatile anesthetics. 


\section{References}

1. Gepstein R, Arinzon Z, Folman Y, Shuval I, Shabat S. Efficacy and complications of patient-controlled analgesia treatment after spinal surgery. Surg Neurol 2007; 67: 360-6.

2. Fisher CG, Belanger L, Gofton EG, Umedaly HS, Noonan VK, Abramson C, et al. Prospective randomized clinical trial comparing patientcontrolled intravenous analgesia with patient-controlled epidural analgesia after lumbar spinal fusion. Spine (Phila Pa 1976) 2003; 28: 739-43.

3. Jeon YS, Kim YS, Joo JD, In JH, Choi JW, Kang EJ, et al. Postoperative Pain Control using Intravenous Patient Controlled Analgesia in Cesarean Section and Hysterectomy. Korean J Anethesiol 2007; 52: 166-71.

4. Jellish WS, Leonetti JP, Sawicki K, Anderson D, Origitano TC. Morphine/ondansetron PCA for postoperative pain, nausea, and vomiting after skull base surgery. Otolaryngol Head Neck Surg 2006; 135: 175-81.

5. Watcha MF, White PF. Postoperative nausea and vomiting. Its etiology, treatment, and prevention. Anesthesiology 1992; 77: 16284.

6. Sleath GW, Archer LT. Halothane for controlled hypotension in back surgery. Can Anaesth Soc J 1967; 14: 407-12.

7. Leslie K, Williams DL. Postoperative pain, nausea and vomiting in neurosurgical patients. Curr Opin Anaesthesiol 2005; 18: 461-5.

8. Tramer MR, Reynolds DJ, Moore RA, McQuay HJ. Efficacy, doseresponse, and safety of ondansetron in prevention of postoperative nausea and vomiting: a quantitative systematic review of randomized placebo-controlled trials. Anesthesiology 1997; 87: 1277-89.

9. Kazemi-Kjellberg F, Henzi I, Tramer MR. Treatment of established postoperative nausea and vomiting: a quantitative systematic review. BMC Anesthesiol 2001; 1: 2.

10. Neufeld SM, Newburn-Cook CV. The efficacy of 5-HT3 receptor antagonists for the prevention of postoperative nausea and vomiting after craniotomy: a meta-analysis. J Neurosurg Anesthesiol 2007; 19: 10-7.

11. Fujii Y, Tanaka H, Kawasaki T. Benefits and risks of granisetron versus ramosetron for nausea and vomiting after breast surgery: a randomized, double-blinded, placebo-controlled trial. Am J Ther 2004; 11: 278-82.

12. Choi YS, Shim JK, Yoon do H, Jeon DH, Lee JY, Kwak YL. Effect of ramosetron on patient-controlled analgesia related nausea and vomiting after spine surgery in highly susceptible patients: comparison with ondansetron. Spine (Phila Pa 1976) 2008; 33 : E602-6.

13. Kim EJ, Ko JS, Kim CS, Lee SM, Choi DH. Combination of antiemetics for the prevention of postoperative nausea and vomiting in high-risk patients. J Korean Med Sci 2007; 22: 878-82.

14. Biswas BN, Rudra A. Comparison of granisetron and granisetron plus dexamethasone for the prevention of postoperative nausea and vomiting after laparoscopic cholecystectomy. Acta Anaesthesiol Scand 2003; 47: 79-83.

15. Villalon A, Chan V. Multicenter, randomized trial of ramosetron plus dexamethasone versus ramosetron alone in controlling cisplatin-induced emesis. Support Care Cancer 2004; 12: 58-63.

16. Apfel CC, Laara E, Koivuranta M, Greim CA, Roewer N. A simplified risk score for predicting postoperative nausea and vomiting: conclusions from cross-validations between two centers. Anesthesiology 1999; 91: 693-700.

17. Myles PS, Williams DL, Hendrata M, Anderson H, Weeks AM. Patient satisfaction after anaesthesia and surgery: results of a prospective survey of 10,811 patients. Br J Anaesth 2000; 84: 6-10.

18. Palazzo MG, Strunin L. Anaethesia and emesis: I. Etiology. Can Anaesth Soc J 1984; 31: 178-87.

19. Cherian VT, Smith I. Prophylactic ondansetron does not improve patient satisfaction in women using PCA after Caesarean section. Br J Anaesth 2001; 87: 502-4.

20. Habib AS, Gan TJ. Combination therapy for postoperative nausea and vomiting - a more effective prophylaxis? Ambul Surg 2001; 9: 59-71.

21. Paech MJ, Rucklidge MW, Lain J, Dodd PH, Bennett EJ, Doherty DA. Ondansetron and dexamethasone dose combinations for prophylaxis against postoperative nausea and vomiting. Anesth Analg 2007; 104: 808-14.

22. Wang JJ, Ho ST, Lee SC, Liu YC, Ho CM. The use of dexamethasone for preventing postoperative nausea and vomiting in females undergoing thyroidectomy: a dose-ranging study. Anesth Analg 2000; 91: 1404-7.

23. Coloma M, White PF, Markowitz SD, Whitten CW, Macaluso AR, Berrisford SB, et al. Dexamethasone in combination with dolasetron for prophylaxis in the ambulatory setting: effect on outcome after laparoscopic cholecystectomy. Anesthesiology 2002; 96: 1346-50.

24. Young SN. Mechanism of decline in rat brain 5-hydroxytryptamine after induction of liver tryptophan pyrrolase by hydrocortisone: roles of tryptophan catabolism and kynurenine synthesis. Br J Pharmacol 1981; 74: 695-700.

25. Fredrikson M, Hursti T, Furst CJ, Steineck G, Borjeson S, Wikblom M, et al. Nausea in cancer chemotherapy is inversely related to urinary cortisol excretion. Br J Cancer 1992; 65: 779-80.

26. Sanchez-Ledesma MJ, Lopez-Olaondo L, Pueyo FJ, Carrascosa F, Ortega A. A comparison of three antiemetic combinations for the prevention of postoperative nausea and vomiting. Anesth Analg 2002; 95: 1590-5.

27. Apfel CC, Korttila K, Abdalla M, Kerger H, Turan A, Vedder I, et al. A factorial trial of six interventions for the prevention of postoperative nausea and vomiting. N Engl J Med 2004; 350: 2441-51.

28. Habib AS, White WD, Eubanks S, Pappas TN, Gan TJ. A randomized comparison of a multimodal management strategy versus combination antiemetics for the prevention of postoperative nausea and vomiting. Anesth Analg 2004; 99: 77-81. 